\title{
Growth-selective predation hypothesis revisited for larval anchovy in offshore waters: cannibalism by juveniles versus predation by skipjack tunas
}

\author{
Akinori Takasuka ${ }^{1, *}$, Yoshioki Oozeki ${ }^{1}$, Ryo Kimura ${ }^{2}$, Hiroshi Kubota ${ }^{1}{ }_{\text {Ichiro Aoki }}{ }^{3}$ \\ ${ }^{1}$ National Research Institute of Fisheries Science, Fisheries Research Agency, 2-12-4 Fukuura, Kanazawa, Yokohama, \\ Kanagawa 236-8648, Japan \\ ${ }^{2}$ Agriculture, Forestry and Fisheries Research Council, Ministry of Agriculture, Forestry and Fisheries, 1-2-1 Kasumigaseki, \\ Chiyoda, Tokyo 100-8950, Japan \\ ${ }^{3}$ Department of Aquatic Bioscience, Graduate School of Agricultural and Life Sciences, University of Tokyo, \\ 1-1-1 Yayoi, Bunkyo, Tokyo 113-8657, Japan
}

\begin{abstract}
The 'growth-selective predation' hypothesis was revisited for larval Japanese anchovy Engraulis japonicus, focusing on larval cannibalism by juveniles and larval predation by skipjack tunas Katsuwonus pelamis, in offshore waters. Larval anchovy and predators were captured simultaneously in June 1997 and in May 2000 in the western North Pacific. Growth rates estimated through otolith microstructure analysis, as well as somatic sizes, were compared between the ingested larvae from the stomach contents of the predators and the surviving larvae from the original population. Size-selective mortality was directed negatively for cannibalism by juveniles and positively for predation by skipjack tunas. The cannibalised larvae had lower growth rates than the larvae from the original population in the same larval size range. On the other hand, a similar comparison showed no differences in larval growth rates for predation by skipjack tunas. Larval cannibalism by juveniles would potentially regulate growth-selective survival as well as survival rate itself during early life history stages of Japanese anchovy, while predation by skipjack tunas would influence survival rate itself but not growth-selective survival.
\end{abstract}

KEY WORDS: Growth-selective predation hypothesis $\cdot$ Growth rate $\cdot$ Predation mortality $\cdot$ Otolith microstructure $\cdot$ Larval Japanese anchovy $\cdot$ Larval cannibalism $\cdot$ Juvenile $\cdot$ Skipjack tuna

\section{INTRODUCTION}

Faster-growing fish larvae are assumed to be more likely to survive in the sea. According to this 'growthmortality' hypothesis (Anderson 1988), growth rate during early life history stages can be a regulator of recruitment dynamics of fish. Why do faster-growing individuals gain survivorship? To date, 3 factors can serve to explain such a paradigm: size (body size), time (stage duration) and growth rate (per se rate) (Takasuka et al. 2003, 2004). The size-based concept has been labelled the 'bigger is better' hypothesis (Miller et al. 1988). This theory postulates the existence of negative size-selective mortality (i.e. higher mortality for smaller fish). The time-based concept is the 'stage duration' hypothesis (Chambers \& Leggett 1987, Houde 1987), which postulates that faster-growing larvae will have a higher development rate and thus experience a decreased cumulative mortality rate by shortening the high mortality larval period. Such survival advantages of higher growth rate have been supported by field investigations (e.g. Meekan \& Fortier 1996, Hare \& Cowen 1997, Searcy \& Sponaugle 2001, Allain et al. 2003, Oozeki et al. 2003). Meanwhile, contrary evidence against negative size-selective mortality has recently presented and apparent size effects may be confused with age or 
developmental stage effects (Litvak \& Leggett 1992, Pepin et al. 1992, Pepin 1993, Leggett \& DeBlois 1994). Also, faster-developing individuals may face up to one predator field, after passing through another. In theory, 2 growth-related scenarios explain the growth-survival relationship indirectly by translating growth rate into size or time. Moreover, until recently, no direct evidence had yet been obtained to identify the direct source of mortality. On the other hand, the recently proposed 'growth-selective predation' hypothesis (Takasuka et al. 2003, 2004) directly links per se growth rate with predation mortality. In short, faster-growing larvae will be less vulnerable to predation than slower-growing conspecifics, even if they are the same size, at a given moment in the sea. Thus, growth rates themselves have direct impacts on predation mortality, independently of both size-selective mortality and stage duration.

The 'growth-selective predation' hypothesis was proposed with the first snapshot evidence of the growth-predation relationship for larval Japanese anchovy Engraulis japonicus in the shirasu (larval anchovy) fishing ground, just off the coast, in Sagami Bay (Takasuka et al. 2003). However, Japanese anchovy are distributed and spawn widely (Funamoto \& Aoki 2002), and larvae are transported offshore and then northward in the western North Pacific (Takasuka \& Aoki 2002). The 'growth-selective predation' hypothesis remains to be tested in such offshore waters, where pelagic fish larvae are exposed to multiple predator fields (Sugisaki 1996). One of the top fish predators is the skipjack tuna Katsuwonus pelamis, although pelagic juvenile and adult anchovy can also be potential predators (i.e. cannibals). Previous studies on cannibalism in pelagic fish have almost exclusively focused on egg cannibalism (Hunter \& Kimbrell 1980, Alheit 1987, Valdés Szeinfeld 1991, 1993, Köster \& Möllmann 2000), whereas cannibalism of the larval stage of planktivorous small pelagic species has been studied much less (but see Brownell 1985, Folkvord \& Hunter 1986, Booman et al. 1991).

The present study revisited the 'growth-selective predation' hypothesis for larval Japanese anchovy in offshore waters. We first targeted larval cannibalism by juvenile anchovy, which was then compared to the prey-predator interaction between larval anchovy and skipjack tuna in the western North Pacific.

\section{MATERIALS AND METHODS}

Sympatric larval and juvenile Japanese anchovy were both captured simultaneously by the same tow of a frame-type midwater trawl with a mouth area of $16 \mathrm{~m}^{2}$ and a stretch mesh size of $8 \mathrm{~mm}$ (Aoki et al. 2000) in the western North Pacific on 11 June 1997. During nighttime, the net was towed almost horizontally for $30 \mathrm{~min}$ at a depth of 10 to $25 \mathrm{~m}$ at Stn A on the front of the Kuroshio Extension (Table 1, Fig. 1). During another cruise, larval anchovy were captured by a neuston net with a mouth area of $0.975 \mathrm{~m}^{2}$ and a mesh size of $0.45 \mathrm{~mm}$ (Oozeki et al. 2001) on 15 May 2000. During the daytime, the net was towed horizontally for $10 \mathrm{~min}$ at the surface layer 3 times at Stn B in the Kuroshio-Oyashio transition region (Table 1, Fig. 1). Concurrently, we sampled skipjack tunas by trolling lines at the same station. Fork length (FL) of skipjack tuna was measured to the nearest $1 \mathrm{~cm}$ on board. Larval and juvenile anchovy were preserved in $90 \%$ ethanol, and guts of skipjack tunas in $90 \%$ ethanol or $10 \%$ formalin immediately after sampling.

Standard length (SL) was measured to the nearest $0.1 \mathrm{~mm}$ for each larval and juvenile anchovy. Stomach contents of juvenile anchovy $(\mathrm{n}=120)$ and skipjack tunas $(\mathrm{n}=9$ ) were sorted for larval anchovy under a binocular microscope. For juvenile anchovy, stomach content index (SCI\%) was calculated as the stomach

Table 1. Sampling information and sample profile for larval Japanese anchovy Engraulis japonicus and predatory fish, juvenile anchovy and skipjack tuna Katsuwonus pelamis. Ingested larvae: the larvae ingested by the predators, i.e. the larvae dissected from the stomach contents of the predators; Original larvae: the larvae from the original population, i.e. the larvae captured concurrently with the predators. Standard lengths (SLs) of the ingested larvae were restored from the actually measured otolith radius data. FL: fork length; $n$ : number for growth analysis; $n$ : occurrence from the stomach contents of the predators

\begin{tabular}{|c|c|c|c|c|}
\hline Information & \multicolumn{2}{|c|}{ Stn A } & \multicolumn{2}{|c|}{ Stn B } \\
\hline Date & \multicolumn{2}{|c|}{11 June 1997} & \multicolumn{2}{|c|}{15 May 2000} \\
\hline Time & \multicolumn{2}{|c|}{$19: 40-20: 20 \mathrm{~h}$} & \multicolumn{2}{|c|}{$09: 30-17: 30 \mathrm{~h}$} \\
\hline Location & \multicolumn{2}{|c|}{$35^{\circ} 00^{\prime} \mathrm{N}, 144^{\circ} 30^{\prime} \mathrm{E}$} & \multicolumn{2}{|c|}{$38^{\circ} 08^{\prime} \mathrm{N}, 144^{\circ} 34^{\prime} \mathrm{E}$} \\
\hline Predator & \multicolumn{2}{|c|}{ Juvenile Engraulis japonicus } & \multicolumn{2}{|c|}{ Katsuwonus pelamis } \\
\hline $\mathrm{n}$ & \multicolumn{2}{|c|}{120} & \multicolumn{2}{|c|}{9} \\
\hline Size (mm) & \multicolumn{2}{|c|}{$35.7-61.3(\mathrm{SL})$} & \multicolumn{2}{|c|}{$450-540$ (FL) } \\
\hline Prey (Engraulis japonicus) & Ingested larvae & Original larvae & Ingested larvae & Original larvae \\
\hline$n\left(n^{\prime}\right)$ & $33(85)$ & 100 & $12(59)$ & 47 \\
\hline Size (mm) & $13.6-20.2$ & $13.1-31.1$ & $22.2-26.2$ & $14.4-27.4$ \\
\hline
\end{tabular}




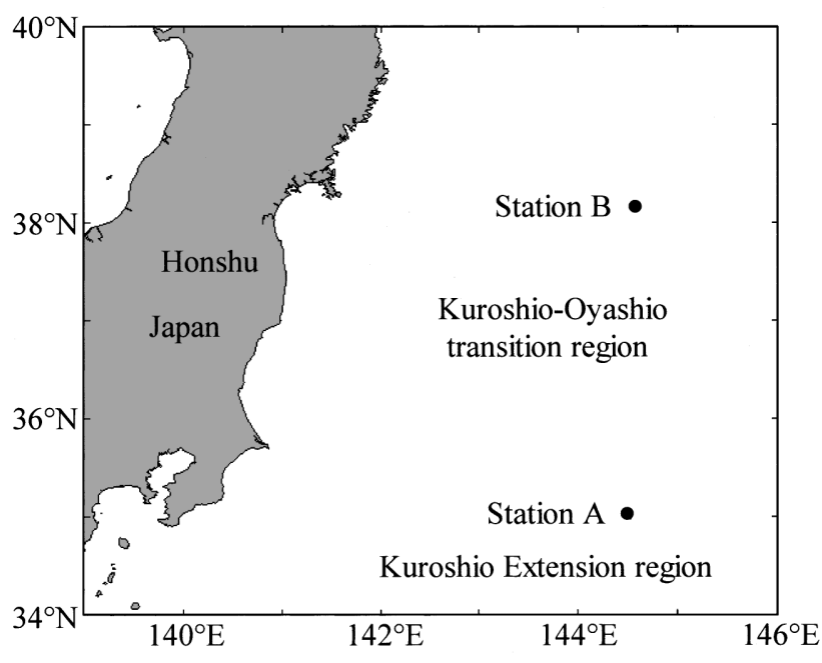

Fig. 1. Sampling stations for larval and juvenile Japanese anchovy Engraulis japonicus in June 1997 (Stn A) and larval anchovy and skipjack tunas Katsuwonus pelamis in May 2000 (Stn B) in the western North Pacific

content wet weight divided by body wet weight. In addition, larval anchovy contribution to the stomach content in wet weight (\%) was calculated.

The larvae dissected from the stomach contents of the predators should be the larvae actually ingested by the predators (ingested larvae); the larvae captured concurrently with the predators were regarded as the temporarily surviving larvae from the assumed original population (original larvae). This assumption was ensured by the same-tow sampling of the sympatric larval and juvenile anchovy. We separately sampled larval anchovy and skipjack tunas, but collections were made simultaneously.

Sagittal otolith microstructure analysis was conducted to estimate larval growth rates, according to Takasuka et al. (2003). Sagittal otoliths were extracted from both the ingested larvae and original larvae. Maximum otolith radius (OR) and each daily growth increment width were measured to the nearest $0.1 \mu \mathrm{m}$, using an otolith measurement system (RATOC System Engineering). Prior to growth calculations, SLs of the ingested larvae were restored from the actually measured OR data using the allometric OR-SL relationship of the corresponding original larvae. This SL restoration process has been validated not to lead to any serious bias in size and growth comparison (see Takasuka et al. 2003 for details). Daily growth rate at each daily age $\left(\mathrm{mm} \mathrm{d}^{-1}\right)$ was back-calculated by the biological intercept method (Campana 1990, Campana \& Jones 1992), using an allometric OR-SL formula at the individual level, with SL at the first ring deposition fixed at $5.6 \mathrm{~mm}$ (Fukuhara 1983). We adopted recent 5 d mean growth rates directly before capture or predation as a proxy for survival potential factors. Size-selective and growth-rate-selective predation mortalities were tested by comparing somatic sizes and recent growth rates between the ingested larvae and the corresponding original larvae.

\section{RESULTS}

Larval cannibalism was observed for 31 (25.8\%) of 120 juvenile anchovy of 35.7 to $61.3 \mathrm{~mm}$ SL. A total of 85 larval anchovy (ingested larvae) were dissected from their stomach contents and sagittal otoliths were extracted from 33 ingested larvae for growth analysis (Table 1). The other components of the juvenile stomach contents were mainly copepods such as Oncaea and Sapphirina, and no fish larvae were observed other than larval anchovy. A juvenile of $42.8 \mathrm{~mm}$ SL was the smallest to show cannibalism (Fig. 2). The SCI values were $10.1 \pm 3.4 \%$ (mean $\pm \mathrm{SD}$ ) for cannibal juveniles $(\mathrm{n}=31)$, which were significantly higher than $5.1 \pm 2.2 \%$ for non-cannibal juveniles $>42.8 \mathrm{~mm}$ SL ( $\mathrm{n}=47$ ) (Welch's $t$-test, $\mathrm{p}<0.001$ ). Larval anchovy made up 10.0 to $85.7 \%$ (mean $=32.3 \%$ ) of the stomach contents in wet weight for cannibal juveniles. On the other hand, a total of 59 larval anchovy and 7 unidentified fish larvae occurred from 7 of 9 skipjack tunas of 45 to $54 \mathrm{~cm} \mathrm{FL}$ and otoliths were available for 12 ingested larval anchovy (Table 1). Almost all of the ingested larvae from both juveniles and skipjack tunas (82 of 85 and 52 of 59) were observed to be at least partially digested.

The restored SLs of the ingested larvae were included in the range of the measured SLs of the corresponding original larvae and the modal SLs seemed similar for both types of prey-predator interactions (Fig. 3). The SL distributions, however, apparently differed between the ingested larvae and original larvae. The mean SL of the ingested larvae was slightly lower than that of the original larvae $(17.5 \pm 1.4$ vs $18.9 \pm$ $3.1 \mathrm{~mm}$ ) for cannibalism, while the mean SL of the ingested larvae was greater than that of the original larvae $(23.9 \pm 1.2$ vs $22.0 \pm 3.1)$ for predation by skipjack tunas. For cannibalism, 32 of 33 ingested larvae were smaller than $20 \mathrm{~mm}$, in spite of the wider SL range (13.1 to $31.1 \mathrm{~mm}$ ) of the original larvae $(\mathrm{n}=100)$. For predation by skipjack tunas, conversely, all of the ingested larvae ( $\mathrm{n}=12$ ) were larger than $20 \mathrm{~mm}$, while the SLs of the original larvae $(n=47)$ ranged from 14.4 to $27.4 \mathrm{~mm}$. The differences in SLs seemed slight but were confirmed statistically for both comparisons (Mann-Whitney's $U$-test, $\mathrm{p}=0.007$ and 0.020 ).

Fig. 4 shows the recent $5 \mathrm{~d}$ mean growth rates plotted against larval sizes for growth comparison at the same size. Recent growth rates were positively cor- 

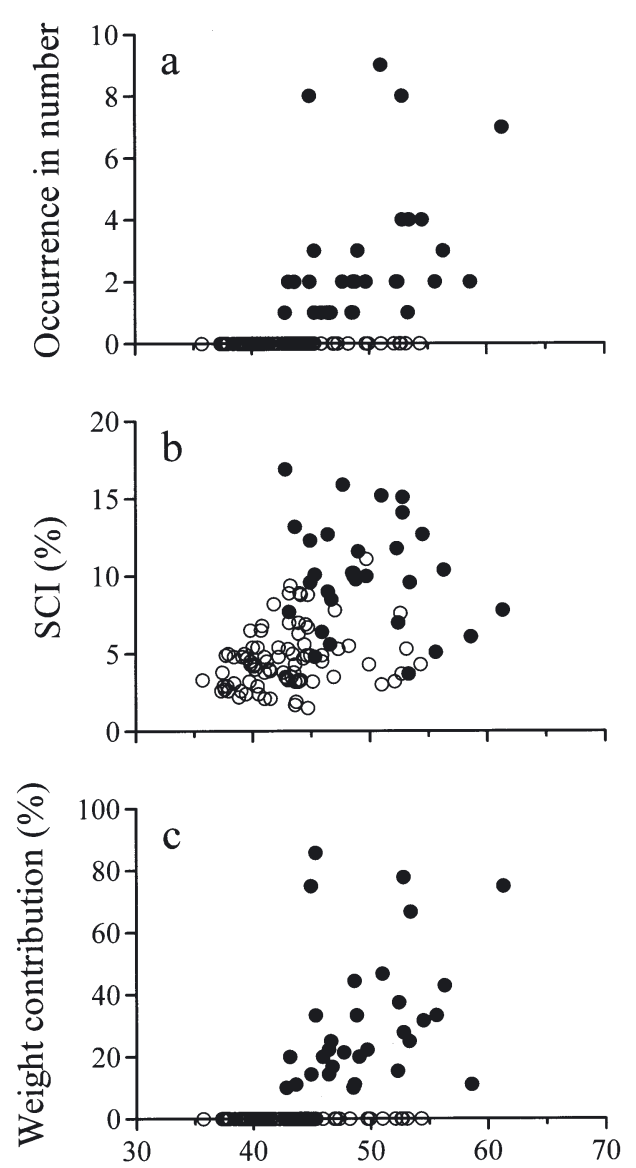

Standard length $(\mathrm{mm})$

Fig. 2. Engraulis japonicus. Ontogenetic features of larval cannibalism by juvenile anchovy. (a) Occurrence of the ingested larvae in number with juvenile size; (b) comparison of stomach content index (SCI) between the cannibal juveniles and non-cannibal juveniles; (c) larval anchovy weight contribution to the stomach contents of juveniles in wet weight. Data are shown separately for the cannibal juveniles $(\bullet)$ and non-cannibal juveniles (O)

related with larval sizes for the original larvae (linear regression analysis, $\mathrm{p}<0.001$ ), but not for the ingested larvae ( $p>0.05)$, making it impossible to compare regressions. Thus, we compared recent growth rates between the ingested larvae and original larvae within the common SL range. For cannibalism, the recent growth rates of the ingested larvae $\leq 20 \mathrm{~mm}(\mathrm{n}=32)$ were $0.50 \pm 0.07$ (mean $\pm \mathrm{SD}$ ) $\mathrm{mm} \mathrm{d}^{-1}$, which were significantly lower than those of the corresponding original larvae $\leq 20 \mathrm{~mm}(\mathrm{n}=84), 0.55 \pm 0.10 \mathrm{~mm} \mathrm{~d}^{-1}$ (Student's $t$-test, $\mathrm{p}=0.005$ ). On the other hand, the similar comparison showed no significant differences in recent growth rates between the ingested larvae $\geq 20 \mathrm{~mm}\left(0.50 \pm 0.08 \mathrm{~mm} \mathrm{~d}^{-1}, \mathrm{n}=12\right)$ and original larvae $\geq 20 \mathrm{~mm}\left(0.50 \pm 0.06 \mathrm{~mm} \mathrm{~d}^{-1}, \mathrm{n}=39\right)$ for predation by skipjack tunas (Student's $t$-test, $\mathrm{p}=0.912$ ).

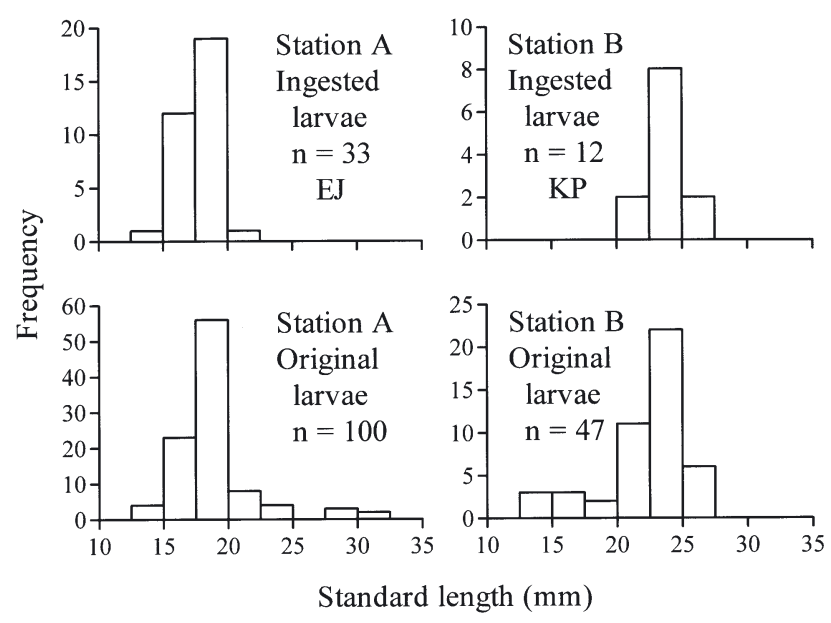

Fig. 3. Engraulis japonicus. Comparison of standard length (SL) frequencies between the ingested larvae (upper panels) and the larvae from the original population (lower panels) for cannibalism by juvenile anchovy (EJ: left) and predation by skipjack tunas Katsuwonus pelamis (KP: right). Station, sample size and predator (only for the ingested larvae) are indicated in each panel. SLs of the 2 ingested larvae groups were separately restored from the actually measured otolith radius (OR) data, using the allometric OR-SL relationship of the 2 original larvae groups: $\mathrm{SL}=1.447 \mathrm{OR}^{0.555}(\mathrm{n}=100$, $\left.\mathrm{r}^{2}=0.846, \mathrm{p}<0.001\right)$ for the original larvae corresponding to the ingested larvae from juvenile conspecifics and $\mathrm{SL}=1.381 \mathrm{OR}^{0.563}\left(\mathrm{n}=47, \mathrm{r}^{2}=0.930, \mathrm{p}<0.001\right)$ for the original larvae corresponding to the ingested larvae from skipjack tunas

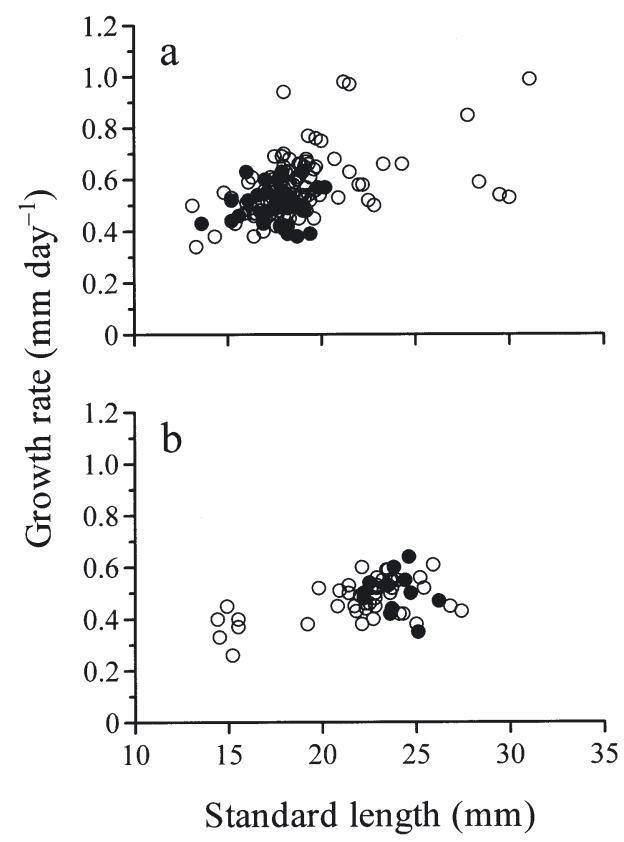

Fig. 4. Engraulis japonicus. Comparison of recent $5 \mathrm{~d}$ mean growth rates plotted against standard length (SL) between the ingested larvae $(\bullet)$ and the larvae from the original population (O) for (a) cannibalism by juvenile anchovy and (b) predation by skipjack tunas Katsuwonus pelamis 


\section{DISCUSSION}

Size-selective mortality of larval Japanese anchovy was directed negatively for cannibalism by juveniles and positively for predation by skipjack tunas (Fig. 3). A possibility of biases due to selectivity of the gear, such as loss of smaller larvae through the mesh, cannot be completely ruled out, but it would not seriously affect the results, since the original larvae well covered the ingested larvae in size and their minimum sizes were almost the same. We could rule out any critical bias due to predation in the trawl cod-end, because of the rarity of fresh condition larvae (see Takasuka et al. 2003 for details). Brownell (1985) reported that Cape anchovy Engraulis capensis of 15 to $35 \mathrm{~mm}$ SL could ingest conspecific larvae of almost half of their own size, the largest that the mouth openings could permit, in an experimental condition. This corresponded well to the upper limit of the prey-predator size ratios observed for cannibalism in the present field study (0.46). Such a gape limitation will lead to a survival advantage for larger larvae (Werner \& Gilliam 1984, Miller et al. 1988). In addition, no juvenile anchovy suffered from cannibalism, suggesting that individuals developing into the juvenile stage faster will experience a lower cannibalism mortality rate. Larger larvae or juveniles will have broken through the 'window' of vulnerability. In this sense, both the 'bigger is better' and 'stage duration' mechanisms might be in operation in larval cannibalism by juveniles.

The case would be different when larval shoals are attacked by skipjack tunas (Fig. 3): larger larvae would have no size advantage. This would also presumably be true for juveniles as they too would be vulnerable. Thus, neither 'bigger is better' nor 'stage duration' mechanisms would be effective in predation by skipjack tunas. Rather, even the disadvantage of larger body size cannot be excluded. A possible factor leading to the phenomenon that bigger is not always better is the encounter rate; however, larval swimming speed would have virtually no effect when a predator's speed largely surpasses a prey's speed (Bailey \& Houde 1989, Litvak \& Leggett 1992, Fuiman \& Magurran 1994). Thus, conspicuousness of larger larvae (Bailey \& Houde 1989) may more effectively contribute to their higher predation mortality rate by skipjack tunas. Such a selection leads to an advantage of more energy gain for a given effort in skipjack tunas.

The ingested larval anchovy had significantly lower recent growth rates than the larvae from the original population in the same size range for cannibalism by juveniles (Fig. 4), providing snapshot evidence to demonstrate the existence of 'growth-selective cannibalism' on larval anchovy by juvenile conspecifics in offshore waters. In contrast, non-growth-selective predation was suggested for the prey-predator interaction between larval anchovy and skipjack tunas, although sample size was rather small. These phenomena are consistent with those detected in the shirasu fishing ground in Sagami Bay, where Japanese jack mackerel Trachurus japonicus, Pacific round herring Etrumeus teres and Japanese anchovy selected slowergrowing larval anchovy, while barracuda Sphyraena pinguis and Japanese sea bass Lateolabrax japonicus preyed upon larvae randomly (Takasuka et al. 2003). In offshore waters, juvenile anchovy are categorised as the growth-selective predator and skipjack tuna as the non-growth-selective predator.

What leads to such predator specificity? Variations in potential for anti-predator behaviours provides the background for the 'growth-selective predation' mechanism. Slower-growing larvae deteriorate physiologically; thus they have lower responsiveness to predator attacks and swimming ability, and tend to be isolated from shoals, finally becoming more vulnerable to predation (Takasuka et al. 2003). As such, faster-growing individuals may succeed in escaping attacks by a smaller predator (juvenile anchovy) while they cannot escape attacks by an extremely larger predator (skipjack tuna) since variations in larval activities should be nonsignificant against attack performance of skipjack tunas. Predator-specific 'growth-selective predation' should be due to differences in feeding strategy, for example, opportunistic feeding of planktivorous predators versus specialistic feeding of piscivorous predators.

Larval and juvenile anchovy were mixed at a rate of 292 versus 68 (larvae versus juvenile), estimated from a subsample (data not shown). According to the occurrence of 85 larvae from 120 juveniles, our rough estimation led to an expectation that ca. $16.5 \%$ of larval anchovy could be cannibalised by juveniles instantaneously. The consumption rate due to cannibalism is expected to be considerable. If so, does larval cannibalism by juveniles negatively affect the final recruitment success? Cannibalism is a focal topic as a densitydependent self-regulator and an adaptation under a trade off between energy gain of predatory conspecifics and mortality of prey conspecifics at the population level (Valdés Szeinfeld 1991, 1993). If slowergrowing larvae are also intensively removed by the other predators in offshore waters, intrapopulation removal of such potentially fatal larvae would not, ultimately, be critical to the final recruitment success. Instead, it will provide a considerable energy source for juvenile conspecifics. This may be neither a genetic character nor an acquired adaptation but rather incidental; however, 'growth-selective cannibalism' would be rational in terms of net profitability at the population level in the event. 
In conclusion, larval cannibalism by juveniles would potentially regulate growth-selective survival as well as survival rate itself during early life history stages, while predation by skipjack tunas would influence survival rate itself but not growth-selective survival. Predator field and predation pressure are to be estimated in future studies in order to clarify the picture of survival in offshore waters.

Acknowledgements. We sincerely thank K. M. Bailey (Alaska Fisheries Science Center) for his critical and constructive comments on an earlier draft. Also, the paper has been polished up through discussion with T. Yamakawa, H. Tanaka (University of Tokyo), T. Akamine and M. Suda (Fisheries Research Agency). Our field samplings were supported by the officers and crew of the RV 'Hakuho-maru' (1997) and 'Soyo-maru' (2000) and T. Funamoto (Fisheries Research Agency). Finally, the paper was improved by the detailed comments of 3 anonymous referees.

\section{LITERATURE CITED}

Alheit J (1987) Egg cannibalism versus egg predation: their significance in anchovies. S Afr J Mar Sci 5:467-470

Allain G, Petitgas P, Grellier P, Lazure P (2003) The selection process from larval to juvenile stages of anchovy (Engraulis encrasicolus) in the Bay of Biscay investigated by Lagrangian simulations and comparative otolith growth. Fish Oceanogr 12:407-418

Anderson JT (1988) A review of size dependent survival during pre-recruit stages of fishes in relation to recruitment. J Northwest Atl Fish Sci 8:55-66

Aoki I, Miura T, Imai N, Komatsu T (2000) Sampling large larvae and juveniles of pelagic fish with a frame-type midwater trawl. Nippon Suisan Gakkaishi 66:10-17

Bailey KM, Houde ED (1989) Predation on eggs and larvae of marine fishes and the recruitment problem. Adv Mar Biol 25:1-83

Booman C, Folkvord A, Hunter JR (1991) Responsiveness of starved northern anchovy Engraulis mordax larvae to predation attacks by adult anchovy. Fish Bull 89:707-711

Brownell CL (1985) Laboratory analysis of cannibalism by larvae of the Cape anchovy Engraulis capensis. Trans Am Fish Soc 114:512-518

Campana SE (1990) How reliable are growth back-calculations based on otoliths? Can J Fish Aquat Sci 47:2219-2227

Campana SE, Jones CM (1992) Analysis of otolith microstructure data. Can Spec Publ Fish Aquat Sci 117:73-100

Chambers RC, Leggett WC (1987) Size and age at metamorphosis in marine fishes: an analysis of laboratory-reared winter flounder (Pseudopleuronectes americanus) with a review of variation in other species. Can J Fish Aquat Sci 44:1936-1947

Folkvord A, Hunter JR (1986) Size-specific vulnerability of northern anchovy, Engraulis mordax, larvae to predation by fishes. Fish Bull 84:859-869

Fuiman LA, Magurran AE (1994) Development of predator defences in fishes. Rev Fish Biol Fish 4:145-183

Fukuhara O (1983) Development and growth of laboratory reared Engraulis japonica (Houttuyn) larvae. J Fish Biol 23:641-652

Funamoto T, Aoki I (2002) Reproductive biology of Japanese anchovy off the Pacific coast of eastern Honshu, Japan. J Fish Biol 60:154-169

Editorial responsibility: Otto Kinne (Editor),

Oldendorf/Luhe, Germany
Hare JA, Cowen RK (1997) Size, growth, development, and survival of the planktonic larvae of Pomatomus saltatrix (Pisces: Pomatomidae). Ecology 78:2415-2431

Houde ED (1987) Fish early life dynamics and recruitment variability. Am Fish Soc Symp 2:17-29

Hunter JR, Kimbrell CA (1980) Egg cannibalism in the northern anchovy, Engraulis mordax. Fish Bull 78: 811-816

Köster FW, Möllmann C (2000) Egg cannibalism in Baltic sprat Sprattus sprattus. Mar Ecol Prog Ser 196:269-277

Leggett WC, DeBlois E (1994) Recruitment in marine fishes: is it regulated by starvation and predation in the egg and larval stages? Neth J Sea Res 32:119-134

Litvak MK, Leggett WC (1992) Age and size-selective predation on larval fishes: the bigger-is-better hypothesis revisited. Mar Ecol Prog Ser 81:13-24

Meekan MG, Fortier L (1996) Selection for fast growth during the larval life of Atlantic cod Gadus morhua on the Scotian Shelf. Mar Ecol Prog Ser 137:25-37

Miller TJ, Crowder LB, Rice JA, Marschall EA (1988) Larval size and recruitment mechanisms in fishes: toward a conceptual framework. Can J Fish Aquat Sci 45: $1657-1670$

Oozeki Y, Kimura R, Kubota H, Ishida M (2001) Modified neuston net for collecting larvae and juveniles of Pacific saury, Cololabis saira. Bull Jpn Soc Fish Oceanogr 65: $1-5$

Oozeki Y, Watanabe Y, Kurita Y, Nakata K, Kitagawa D (2003) Growth rate variability of Pacific saury, Cololabis saira, larvae in the Kuroshio waters. Fish Oceanogr 12:419-424

Pepin P (1993) An appraisal of the size-dependent mortality hypothesis for larval fish: comparison of a multispecies study with an empirical review. Can J Fish Aquat Sci 50: 2166-2174

Pepin P, Shears TH, de Lafontaine Y (1992) Significance of body size to the interaction between a larval fish (Mallotus villosus) and a vertebrate predator (Gasterosteus aculeatus). Mar Ecol Prog Ser 81:1-12

Searcy SP, Sponaugle S (2001) Selective mortality during the larval-juvenile transition in two coral reef fishes. Ecology 82:2452-2470

Sugisaki H (1996) Distribution of larval and juvenile Japanese sardine (Sardinops melanostictus) in the western North Pacific and its relevance to predation on these stages. In: Watanabe Y, Yamashita Y, Oozeki Y (eds) Survival strategies in early life stages of marine resources. AA Balkema, Rotterdam, p 261-270

Takasuka A, Aoki I (2002) Growth rates of larval stage of Japanese anchovy Engraulis japonicus and environmental factors in the Kuroshio Extension and Kuroshio-Oyashio transition regions, western North Pacific Ocean. Fish Sci 68(Suppl I):445-446

Takasuka A, Aoki I, Mitani I (2003) Evidence of growthselective predation on larval Japanese anchovy Engraulis japonicus in Sagami Bay. Mar Ecol Prog Ser 252:223-238

Takasuka A, Aoki I, Mitani I (2004) Three synergistic growthrelated mechanisms in the short-term survival of larval Japanese anchovy Engraulis japonicus in Sagami Bay. Mar Ecol Prog Ser 270:217-228

Valdés Szeinfeld E (1991) Cannibalism and intraguild predation in clupeoids. Mar Ecol Prog Ser 79:17-26

Valdés Szeinfeld E (1993) The energetics and evolution of intraspecific predation (egg cannibalism) in the anchovy Engraulis capensis. Mar Biol 115:301-308

Werner EE, Gilliam JF (1984) The ontogenetic niche and species interactions in size-structured populations. Annu Rev Ecol Syst 15:393-425

Submitted: December 22, 2003; Accepted: June 22, 2004

Proofs received from author(s): September 2, 2004 